\title{
Mapping the avalanche risk: from survey to cartographic production. The avalanche bulletin of the Meteomont Service of the Alpine Troops Command
}

\author{
Aurora Rapisarda ${ }^{a^{*}}$, Andrea Marco Raffaele Pranzo ${ }^{\text {a }}$ \\ ${ }^{a}$ University of Trento, aurora.rapisarda@unitn.it, andrea.pranzo@unitn.it \\ * Corresponding author
}

\begin{abstract}
:
During the last decades, the process of explaining life-threatening natural hazards to the public has become a major public issue from the point of view of effective prevention policies. The avalanche risk and the communication methods aimed at its forecasting and prevention constitute the focus of this paper. Among the strategies for an effective communication of environmental risks, cartography plays a pivotal role. It has proved to be essential not only for communication purposes, but also for the planning of prompt and efficient preventive interventions; in so doing, it contributes to the reduction of avalanche-caused damages and deaths. The paper investigates prevention and forecasting activities of the Meteomont Service of the Alpine Troops Command (COMTA) of Bolzano (capital city of the province of South Tyrol - North Italy), resulting in the daily publication of avalanche bulletins (Bollettini valanghe), which also include hazard maps. Specifically, the phases that contribute to the production of the avalanche bulletin and the embedded avalanche risk maps will be firstly examined; secondly, such maps will be analysed in order to assess their communicative potential for the purpose of a correct interpretation aimed at the effective prevention of snow-related risks in mountain areas. Possible improvement will be proposed on the basis of the experience of several avalanche warning services worldwide.
\end{abstract}

Keywords: Meteomont, avalanche bulletins, hazard maps, avalanche risk communication, meteorological data retrieval

\section{Introduction}

During the last decades, the process of explaining lifethreatening natural hazards to the public has become a major public issue from the point of view of effective prevention policies. However, with regard to weather risk assessment and management, it has been pointed out that, while remarkable developments in science and technology did rapidly improve, the community engagement with disaster prevention initiatives has been declining gradually (Takenouchi, 2020).

Among the strategies for an effective communication of environmental risks, cartography plays a pivotal role. Indeed, as "a body of theoretical and practical knowledge that map-makers employ to construct maps as a distinct mode of visual representation" (Harley, 1989, p. 2), cartography constitutes a fundamental heuristic tool for the analysis and understanding of spatial phenomena, as well as for management and territorial planning policies (Scanu, 2016). In this respect, a high degree of legibility of the conveyed information (Scott, 1998) must be the fundamental requirement not only to enable a prompt intervention, but also to allow experts and the general public to reach a full understanding of the specific risk factors and their placement and dynamics within a given territory. As far as this is concerned, hazard maps have proven to be "fundamental for land-use planning and hazard prevention and serve to determine endangered areas" (Kunz, Hurni, 2008, p. 133).
The avalanche danger, i.e. "the likelihood of occurrence and the possible size of avalanches in a specific region of at least $100 \mathrm{~km}^{2} " 1$, and the communication methods aimed at its forecasting and prevention constitute the focus of this research.

Avalanches are masses of snow moving downslope driven by gravity whose release (Ancey, 2001) and dynamics (Steinkoegler et al., 2014) are strongly controlled by several fixed (topographical) and variable (meteorological) parameters. Fixed factors which could trigger avalanches include mean slope, ground surface roughness, shape and curvature of the starting zone and the orientation of the sun; changes in weather conditions are, for example, snowfalls and the resulting lack of cohesion between snow layers, as well as wind and rain (Ancey, 2001, pp. 320-321).

Avalanches can also be classified according to the type of release. This categorization distinguishes loose snow avalanches, mostly caused by not cohesive surface layer of snow, and slab avalanches, consisting in the release of a cohesive slab of snow due to overloading and existing weakness in the snowpack (Bründl et al., 2010, p. 49).

Even if a single avalanche event cannot be specifically forecast, the avalanche risk, in term of probability of occurrence of the event in a given area, is one of the few natural hazards that can be forecast, at least at a regional

https://www.avalanches.org/education/avalanche-dangerscale/ [19/08/2021]. 
scale ratio (Schweitzer et al., 2015). This information is paramount, as its proper communication, within an efficient tool and throughout a universally understandable language, can outline a good practice of collective management of natural risk, in this very case strongly focused on the individual and institutional prevention of exposure (Höppner et al., 2010).

With regard to this, Murphy (1993) identifies three parameters that define the nature of a "good" weather forecast: consistency - "the correspondence between forecasters' judgments and their forecasts", quality - "the correspondence between the forecasts and the matching observations", and value - "the incremental economic and/or other benefits realized by decision makers through the use of the forecasts" (p. 281). The goodness of a weather forecast is therefore connected not only with forecasters' interpretation of meteorological data, but also with the way they communicate such data to the public, on which their correct understanding depends.

In view of these considerations, both dealing with avalanches forecast and risk prevention, and communicating such information in the most effective and comprehensible way, is becoming crucial for avalanche warning centres worldwide.

Within this epistemological framework, the paper intends to investigate prevention and forecasting activities of the Meteomont Service of the Alpine Troops Command (COMTA) of Bolzano (capital city of the province of South Tyrol - North-eastern Italy), resulting in the daily publication of avalanche bulletins (Bollettini valanghe), which also include hazard maps. Specifically, such maps will be analysed in order to assess their communicative potential for the purpose of a correct interpretation aimed at the effective prevention of snow-related risks in mountain areas. Possible improvement will be proposed on the basis of the experience of several avalanche warning services worldwide (Kunz, Hurni, 2008; Staněk et al., 2010; Martí et al., 2009; Engeset, 2013; Ruesch et al., 2013).

\section{The Meteomont Service of the Alpine Troops Command}

The Meteomont Service - COMTA was founded in 1972 in response to the need to provide military departments with the information support necessary to ensure their safety during training and operational activities in a snowy mountain environment. The Service follows European standards and is part of the European Avalanche Warning Service (EAWS). On a national basis, it has been recognized at the legislative level ${ }^{2}$ as one of the institutions that in Italy officially deals with snow-avalanche prevention and forecasting. Such institutions, called Centri Competenza, are - besides the Meteomont Service of COMTA - the Meteomont Service of the Carabinieri Military Force and the Interregional Association for coordination and documentation of snow and avalanche problems (AINEVA).

\subsection{Mission and structure}

Several activities are carried out by the Meteomont Service. Among these: weather forecast; constant support during training and operational activities of military departments; educational activities in the field of avalanche prevention and forecasting for civilians and military personnel; constant monitoring of meteorological conditions in the Alps and in Abruzzo through a network consisting of automatic meteorological and snow stations as well as manual stations; meteorological support for the Civil Protection and the Air Force Meteorological Service through the provision of data collected through such station network.

Furthermore, the need for scientific insights and educational support led the COMTA to the creation of scientific collaboration agreements with research centres and universities, such as the one signed with the University of Trento - under the scientific supervision of Professor Elena Dai Prà, Head of the Geo-Cartographic Centre for Studies and Documentation (GeCo) of Rovereto (Trento). This agreement, which legitimizes the purposes of this paper, provides for the consolidation of research and educational activities, in particular on topics of common interest ranging from geographical and meteorological subjects, with a focus on avalanches, to cartography and scientific and cultural studies on mountain environments.

The headquarter of the Meteomont Service is located in Bolzano; however, Meteomont's activities are distributed throughout the alpine territory within a network of operational units responsible for specific forecasting areas (Centri Settore) (Fig. 1) located in:

- Turin, at the Alpine Brigade "Taurinense",

- Aosta, at the Alpine Training Centre,

- Bolzano, at the Command and Tactical Supports Unit "Tridentina",

- Brunico, at the 6th Alpine Regiment,

- Belluno, at the 7th Alpine Regiment,

- Udine, at the "Julia" Alpine Brigade,

- L'Aquila, at the 9th Alpine Regiment.

\footnotetext{
2 (Italian law n. 74 of March 21 ${ }^{\text {st }}, 2001$; Directive of the Italian Prime Minister of August 12 $\left.2^{\text {th }}, 2019\right)$, https://www.gazzettaufficiale.it/eli/id/2019/10/02/19A06095/ sg [17/8/2021].
} 


\section{From data collection to bulletins' production ${ }^{3}$}

As mentioned above, the forecasting service relies on a widespread monitoring and gauging system throughout the Western and Eastern Alps and in Abruzzo Region (Central Apennines). Figure 1 represents the location of the weather stations, both automatic and manual, for each operational unit. Additionally, a part of data collection is carried out by a team of experts (nuclei di rilevamento mobile - mobile gauging units) who assess directly on the field the state of the snowpack and any related dangers of potential training areas in a more detailed and localized way.

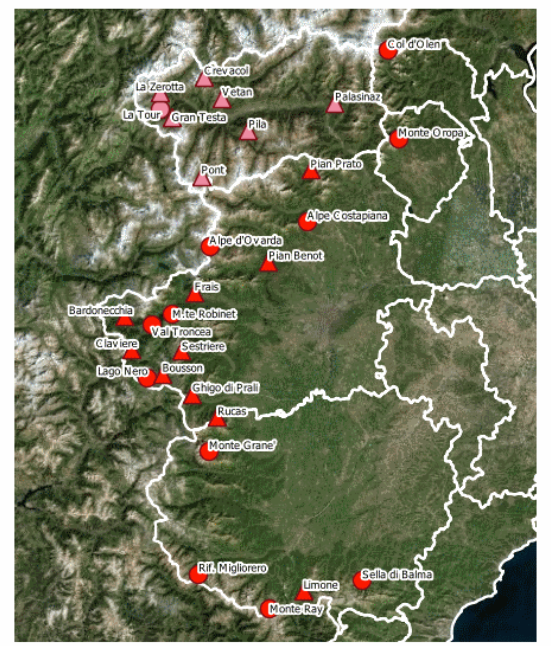

$$
\text { Western Alps }
$$

\section{Meteomont weather stations}

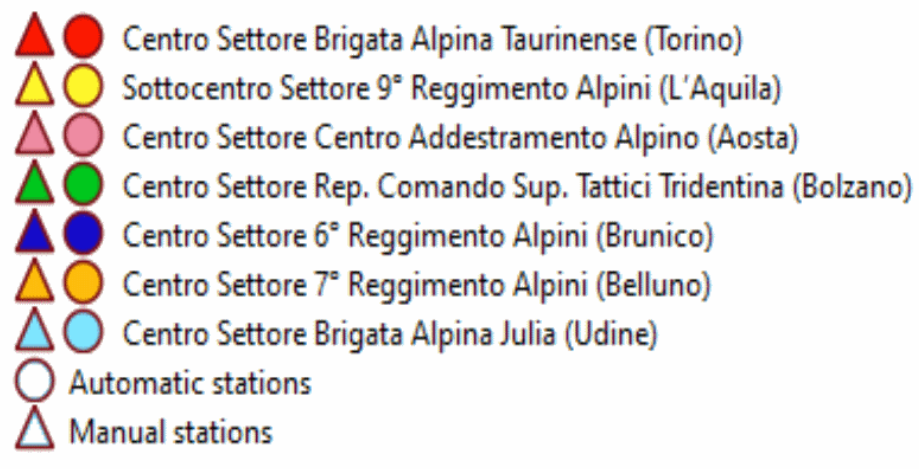

\section{Central Apennines}

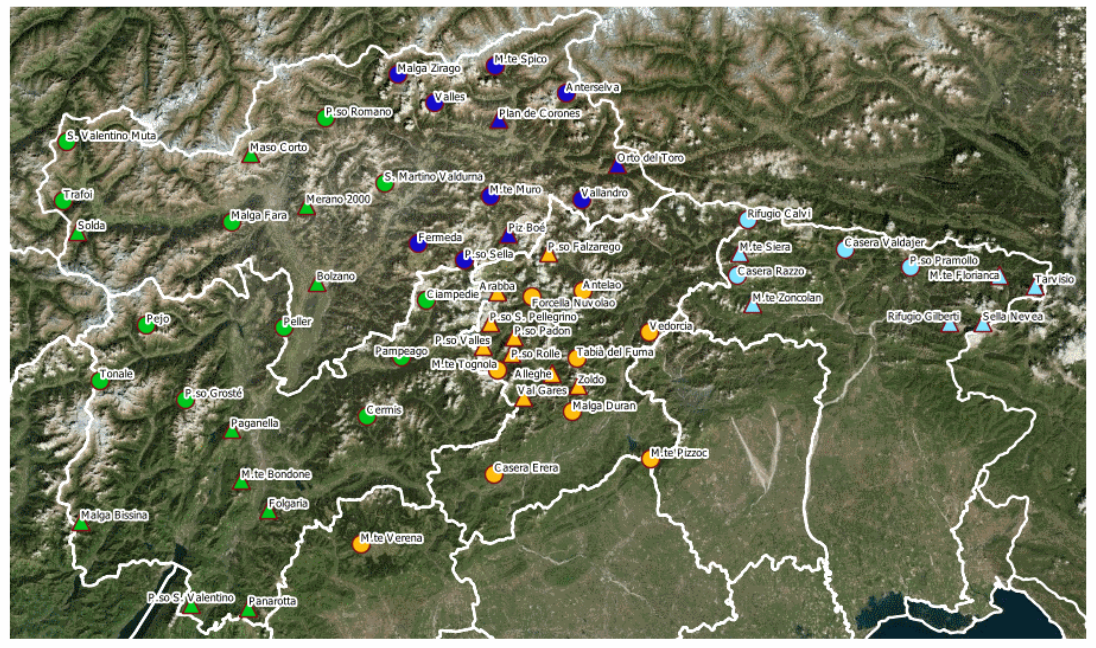

\section{Eastern Alps}

The 46 automatic gauging stations are located at an average altitude of 2500 meters above sea level. These are equipped with sensors that allow the measurement of wind speed and direction, relative humidity, barometric pressure, air temperature and precipitation; as for the snow, they measure the snowpack height as well as its vertical thermal gradient.

The data collected by the various sensors are recorded by specific devices, called data loggers, which are programmed to record data detected by the sensors at defined time intervals (usually, each hour). One of the

Figure 1. Automatic and manual stations of the Meteomont Service (Data source: 2019/2020 Meteomont Seasonal Report. Map produced by the authors).

\footnotetext{
${ }^{3}$ The information contained in the following paragraph is the result of a summary of the data gathered during the site visit at the Meteomont Service of Bolzano, as well as the study of the internal "Relazione stagionale 2019/2020" (2019/2020 Meteomont's Seasonal Report), granted thanks to the agreement between COMTA and the University of Trento.
} 
main problems of transmitting information through devices in a mountain environment is represented by the limitations imposed by the orography itself. For this reason, the transmission of such data, once recorded by the data loggers, is mediated through 19 radio links. The latter transmit the signals to another radio receiver which is located at the headquarters of each relevant operational unit.

The 55 manual gauging stations consist of a portion of fenced flat land to maintain stable the snowpack; the localization is chosen on the basis of precise criteria of orientation, exposure and protection from the winds. These are located both in the valley floors and at high altitudes (generally lower than the previous ones, about 2000 meters above sea level) in order to allow the control and recognition of vertical differentiations of the main meteorological parameters. The measurements are carried out on a daily and weekly basis. The daily survey concerns the acquisition of meteorological, snow and avalanche parameters; the weekly one, on the other hand, consists of a penetrometric and stratigraphic test to investigate the evolution of the structure of the snow layers.

Once the information needed has been collected, the operational units complete the documentation with the meteorological information provided by the Air Force Meteorological Service and with any further information available. Such data is then summarized and collected in the avalanche bulletin that the Meteomont Service publishes every day at $2.00 \mathrm{pm}$.

Indeed, in compliance with the Codice dell'Ordinamento Militare (Italian Military Law), according to which the bulletins are part of the public utility services provided by the Army, their consultation must be made available to the public; therefore, the up-to-date bulletins are also daily issued on the official website: www.meteomont.org.

\subsection{The avalanche bulletins}

The avalanche bulletins are snow assessment reports "which provide on a synoptic scale (no less than 100 $\mathrm{km}^{2}$ ) a simplified picture of snow cover and snowpack stability. These provide the degree of avalanche danger in a given territory at the moment of release and, on the basis of weather forecasts and the possible evolution of the snowpack, also the one expected for the immediate future"4. Their primary objective is to prevent and minimize risks and accidents triggered by avalanches in the Alpine area. However, as in most of the avalanche bulletins, "isolated slopes cannot be evaluated [...] and local details are not considered" (Eckerstorfer, 2007, p.36); therefore, it is always users' responsibility to relate to the degree of danger of the bulletin and the possible avalanche occurrence at the local level.

In this specific case, Meteomont's bulletins show avalanche risk on a regional scale; however, though the information within the single operational unit is mainly general, the location of particularly risky situations within the area of responsibility of the unit - is possibly indicated in detail.

The bulletin of the Meteomont Service is made up of different sections, both textual and graphic-symbolic. With regard to this, it has been pointed out that merely text-based bulletins could result time-consuming and therefore could lead users not to read the whole text and/or not to keep the information in mind. Such bulletins are generally more focused on the description of the hazard, than on the way general users perceive the information. On the other hand, "graphic-based bulletins in combination with short texts allow the users to retain better the information" (Martí et al., 2009, p. 361); these ones are also easier to be understood for a less experienced audience (Ibidem).

The design of the bulletin follows the guidelines introduced by the Consortium of the European Avalanche Warning Services (ARGE EAWS). According to these, the most important information should be on top, less important information at the bottom of the page.

As can be seen from Figure 2 (Avalanche Bulletin relating to the Bolzano operational unit - 25 May 2021), the relevant geographical area - which in this case is represented by the Trentino-Alto Adige region with the exception of Brunico area - is indicated in the upper part. Immediately below the reference unit that produced the bulletin, the time and day of issue, and the period of validity are listed. A significant portion of the bulletin is occupied by the map containing specific symbols and the related legend, followed by the description of the snowpack. A table, on the other hand, contains meteorological information represented in a symbolic way, and namely (from left to right): relevant geographical sub-area, condition of the sky, metereological phenomena, most critical exposures and heights, trend of danger for the following days. In the last column on the right, which is only textual, warnings related to the snowpack conditions and the given metereological information are listed in detail.

\footnotetext{
${ }^{4}$ As stated in the Meteomont's Guideline to the interpretation of the symbols used in the new Meteomont bulletin: "Guida all'interpretazione dei simboli utilizzati nel nuovo bollettino Meteomont",

http://www.meteomont.org/BOLLETTINI/GUIDA_NUOV O_BOLLETTINO.pdf [06/08/2021].
} 


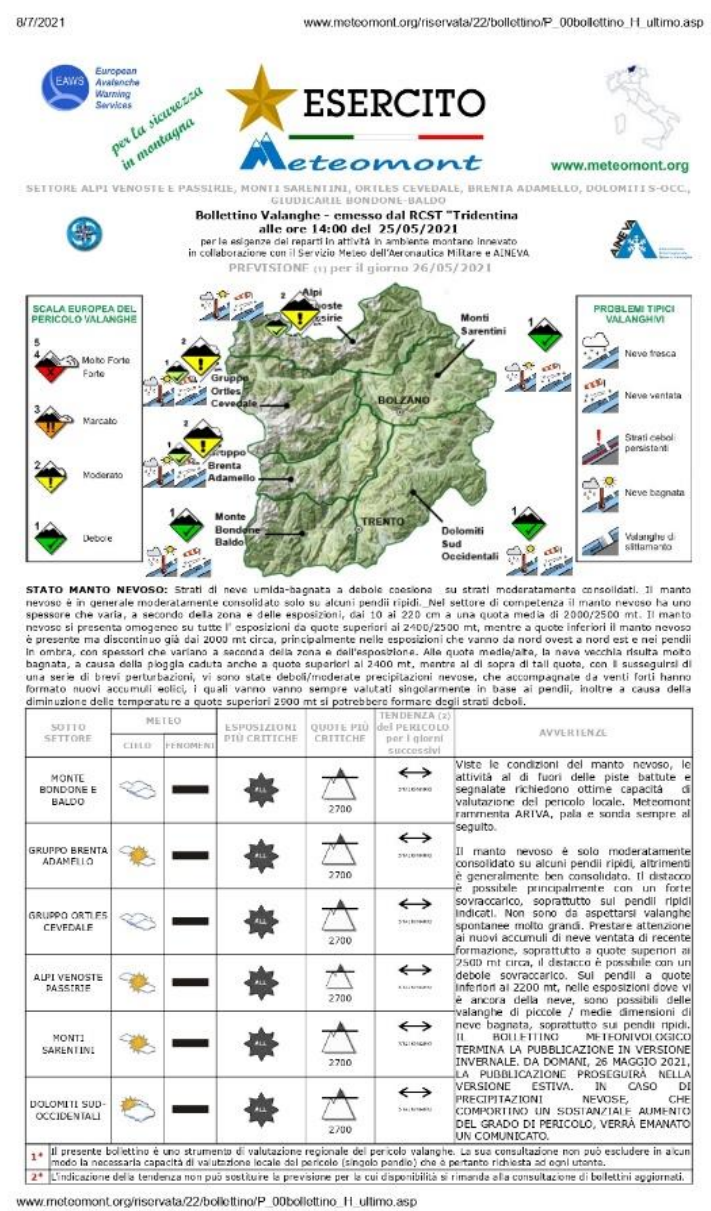

Figure 2. Example of an avalanche bulletin of the Meteomont Service - COMTA (Source: http://www.meteomont.org/5).

\subsection{Avalanche-hazard mapping}

As mentioned before, cartography has proved to be essential not only for communication purposes, but also for the planning of prompt and efficient preventive interventions; in so doing, it contributes to the reduction of avalanche-caused damages and deaths. For this reason, hazard mapping is widely used as an "applied methodology in avalanche hazard assessment and management" (Barbolini et al., 2011, p. 452).

With reference to this, for example in Switzerland the usefulness of avalanche-hazard mapping has been evaluated by comparing the amount of damage caused by avalanche cycles of 1951 and of 1999, i.e. the period of time in which hazard mapping procedures has been developed. Avalanche hazard maps proved to "have successfully prevented many new houses from being built in endangered zones. [...] furthermore, [these] contributed to the reduction of deaths in houses and roads, since the maps are often used in decision to evacuate or to close traffic roads" (Urs, Margreth, 2001, p. 329).

\footnotetext{
${ }^{5}$ http://www.meteomont.org/riservata/22/bollettino/P_00bolletti no_H_ultimo.asp [07/08/2021].
}

A historical collection and mapping of data relating to the location, type, and extent of avalanches in a given area is therefore essential in order to forecast the dynamics and possible occurrence of avalanche disasters. Therefore, despite the lack of historic event records in remote mountain area, "innovative methodology to perform avalanche hazard mapping over large undocumented areas" (Barbolini et al., 2011, p. 451) are being tested. In this respect, the use of Geographic Information Systems (GIS) is crucial for mapping past avalanche activities and runout distances (Delparte et al., 2011); indeed, its use for avalanche-hazard management allow "to analyse and model scenarios that can help explain or even predict possible avalanche occurrences" (Kriz, 2001, p. 80). However, scholars have pointed out that "the art of simplifying real-world three-dimensional space into a spatial model without omitting essential features still remains an important, albeit tricky, task for cartographers" (Ivi, 2001, p. 77); nevertheless, "besides just visualizing what has happened and depicting locations of potential risk, it is now possible within modern cartography to experiment different approaches and to visualize complex variables in a cartographically demanding way" (Ibidem).

In this framework, two types of avalanche hazard maps can be distinguished on the basis of the scale, the contents, and methods used in data collection and processing: on the one hand, "hazard registration maps", i.e. those "containing the maximum boundaries of historically known avalanches, usually [...] compiled from literature, documents, and interviews, and by field investigations and interpretation of photographs" (Barbolini et al., 2011, p. 452); on the other hand, those "outlining zones with different degrees of hazard (usually high, moderate, and low), [...] drawn on the basis of known historic events, geo-morphological investigations, and statistical and/or dynamic computational models" (Ibidem), ascribed to the category "hazard zoning maps" (Sauermoser, 2006).

Meteomont's bulletins contain a cartographic section, which is however only included in winter-season bulletins. Shortly said, avalanche danger is here essentially represented through a combination of meteorological and topographical elements resulting in the hazard map of the depicted area. In this perspective, their importance is twofold: on the one hand the publication of the bulletins lowers the avalanche-caused risks in the mountain environment in the short term; on the other hand, the data collected by the Meteomont Service for the daily production of the bulletins, as well as the related hazard maps, are becoming considerably important since they could contribute to the creation of avalanche hazard zoning maps aimed at minimising risks in medium-long term.

\section{Avalanche risk communication}

An appropriate risk assessment is the basic requirement for reducing avalanche risks. The evaluation must be pursued on two levels: first by those who are actively 
involved in assessing any dangers and communicating them through different means of communication, in our case the Meteomont Service and the avalanche bulletin; secondly by the bulletins' users. However, both levels of interpretation are strictly connected: efficient communication strategies tend to correspond to a correct interpretation of the risk.

The debate on the role of human factors in avalanche accidents has been first put into light by Fesler and Fredston (1994). Their study opened new perspectives on avalanche-triggered damages and deaths; indeed, "the literature and basic research show avalanche accidents are not a terrain, weather, or snowpack problem; avalanche accidents are a human problem" (Atkins, 2000, p. 47). Subsequent studies focused on the identification of the reasons that could lead mountain-goers to incorrectly assess the avalanche risk and therefore to put themselves in dangerous situations; among these, "an individual's propensity toward risk and his or her awareness of forecasted avalanche conditions" (Furman et al, 2010, p. 457). Therefore, avalanche forecasts published by forecasting centres might interact, for example, with an individual's decision to ski a slope or to plan a mountain trip. In light of this, optimizing the communicative effectiveness of avalanche forecasts must be the priority of forecasting centres.

\subsection{Communicative effectiveness of avalanche cartography}

Although the primary purpose of the Meteomont Service's bulletins is to ensure the constant safety of military departments during training and operational activities, as mentioned above, forecasts are part of the public utility services provided by the Armed Forces. Therefore, it is necessary for the bulletins to be clear and understandable not only for Armed Forces users, but also for the general public; maps lend themselves well to the purpose, since these "can make communication between people with different backgrounds much easier" (Staněk et al., 2010, p. 319). Additionally, "especially in a case of spatial information, visual communication is considered one of the most effective types of communication" (Ivi, p. 317).

Using the study conducted by the Laboratory on Geoinformatics and Cartography of the Masaryk University of Brno on cartographic communication optimization (Staněk et al., 2010) as an epistemological basis, the hazard maps of the Meteomont Service's bulletins will be analysed and possible improvements will be proposed; measures implemented by various forecasting centres worldwide, aimed at optimizing the communicative effectiveness of avalanche bulletins, have also been taken into consideration.

Among the possible improvements of cartographic communication effectiveness, Staněk et al. (2010) distinguish improvements of cartographic representation, which can be pursued on two different levels, namely by manipulating the content and/or by manipulating the symbolization, and those of the user interface. For the purpose of this research, improvements of the content and those of the user interface will be treated as one.

\subsection{Possible improvements of cartographic representation and user interface}

The bulletin incorporates a static regional map displaying the orography of the area; it is divided with solid lines in the geographical subareas of the respective operational units, whose toponyms are written out of the map and linked to the corresponding portion of territory; further toponyms are represented by the main geomorphological entities (Fig. 2). As a matter of facts, hazard maps usually mainly consist only of "contour lines, hydrography, land cover (including, in some cases, rock depiction and hill shading), and infrastructure" (Kriz, 2001, p. 78); this is because one of the main problems of maps is the overload of information which can lead users to confusion and misinterpretation of the conveyed message; for this reason, topographic features which are not necessary are usually omitted (Staněk et al., 2010, p. 327). However, the hazard map here represented appears excessively concise. Specifically, the scarcity of topographic "background features, which play the role of spatial reference" (Ibidem) could be an obstacle in understanding for users who are not familiar whit the area. Likewise, the scarce toponymic references could make it difficult to identify intuitively the risk area.

Among the possible approaches to solve visual overload, the use of digital and interactive solutions has been adopted by several forecast centres, such as the Swiss one (Kunz, Hurni, 2008). In this respect, improvements also concern the interface; indeed, digital maps would make "movement inside the map face easy through named locations and active map features" (Staněk et al., 2010, p. 219); the content would also be visually more appealing and easier to interpret.

While topographic features are easily deductible from topographic maps (Kriz, 2001), the various meteorological factors, including the avalanche related ones are much more difficult to represent and visualize (Eckerstorfer, 2015)

As far as the Meteomont's hazard maps is concerned, the avalanche risk is indicated through the use of various symbols and the related legend: on the one hand, icons representing typical avalanche problems (legend on the left), on the other one symbols representing the degree of possible occurrence of avalanche events (legend on the right) (Fig. 3).

A key element in forecast communication effectiveness is also represented by the need of a common language, especially if forecasts for contiguous areas are carried out by different and independent assigned bodies. With regard to this, in the European Alps, about 30 forecast centres issue regional avalanche forecasts; hence to avoid misunderstandings or misinterpretations by users (Techel et al., 2018), communication of avalanche danger is made out according to the European Avalanche Danger Scale (EADS) of the European Avalanche Warning Centre (EAWS). It is a "five-level, ordinarily ascending, 
categorical scale", which, taking into account the changes or the combination of three input variables (i.e. snowpack stability, its spatial distribution and avalanche size) assigns a numeric value (from 5 - very high - to 1 - low) to the avalanche danger"6 (Fig. 3).

\begin{tabular}{|c|c|c|c|c|}
\hline \multicolumn{5}{|c|}{ European Avalanche Danger Scale (2018/19) } \\
\hline & Danger level & Icon & Snowpack stability & Likelihood of triggering \\
\hline 5 & very high & & $\begin{array}{l}\text { The snowpack is poorly } \\
\text { bonded and largely } \\
\text { unstable in general. }\end{array}$ & $\begin{array}{l}\text { Numerous very large and often extremely } \\
\text { large natural avalanches can be expected, } \\
\text { even in moderately steep terrain*. }\end{array}$ \\
\hline & high & & $\begin{array}{l}\text { The snowpack is poorly } \\
\text { bonded on most steep } \\
\text { slopes*. }\end{array}$ & $\begin{array}{l}\text { Triggering is likely, even from low additional } \\
\text { loads**, on many steep slopes*. In some } \\
\text { cases, numerous large and often very large } \\
\text { natural avalanches can be expected. }\end{array}$ \\
\hline 3 & considerable & & $\begin{array}{l}\text { The snowpack is } \\
\text { moderately to poorly } \\
\text { bonded on many steep } \\
\text { slopes*. }\end{array}$ & $\begin{array}{l}\text { Triggering is possible, even from low } \\
\text { additional loads**, particularly on the } \\
\text { indicated steep slopes*. In certain situations } \\
\text { some large, and in isolated cases very large } \\
\text { natural avalanches are possible. }\end{array}$ \\
\hline 2 & moderate & & $\begin{array}{l}\text { The snowpack is only } \\
\text { moderately well bonded } \\
\text { on some steep slopes*; } \\
\text { otherwise well bonded } \\
\text { in general. }\end{array}$ & $\begin{array}{l}\text { Triggering is possible, primarily from high } \\
\text { additional loads**, particularly on the } \\
\text { indicated steep slopes*. Very large natural } \\
\text { avalanches are unlikely. }\end{array}$ \\
\hline 1 & low & & $\begin{array}{l}\text { The snowpack is well } \\
\text { bonded and stable in } \\
\text { general. }\end{array}$ & $\begin{array}{l}\text { Triggering is generally possible only from } \\
\text { high additional loads }{ }^{*} \text { in isolated areas of } \\
\text { very steep, extreme terrain*. Only small and } \\
\text { medium natural avalanches are possible. }\end{array}$ \\
\hline
\end{tabular}

Figure 3. European Avalanche Danger Scale (Source: EAWS) ${ }^{7}$

In the EAWS symbology, the increase in the probability of occurrence of avalanches is represented by changes in colour and icons. As for the colours, the lowest degree of danger is represented in green, the highest one in red. Chromatic choices are related to the ability of colours to carry shared social meanings anchored in people's unconscious; the use of red or other warm colours, for example, is implicitly associated with danger; on the contrary, green and cool colours are mostly linked with safety (Pravossoudovitch et al., 2014).

Additionally, "symbol handling presumes simplicity of drawing, familiarity and clarity of the symbol in relation to meaning, and clear identification of the symbol's importance" (Staněk et al. 2010, p.319). In fact, the symbols used by the EAWS scale apply an iconography also used in other contexts and worldwide recognised. For example, the exclamation mark is used to indicate dangers and warnings, like in the highway code, as well as to mark the presence of toxic substances.

The symbology relating to the most frequent avalanche problems, on the other hand, consists of five icons. Specifically, each of these represents, in a symbolic and clear way (from top to bottom): fresh snow, blowing snow, weak layers in the snowpack, wet snow, slab avalanches.

As can be seen from Figure 2, three symbols are used for each subarea to indicate the degree and type of avalanche risk (one symbol from the EAWS scale and two typical problems). From a graphical point of view, it turns in an

https://www.avalanches.org/education/avalanche-dangerscale/ [07/08/2021].

7 content/uploads/2019/05/European_Avalanche_Danger_Scal e-EAWS.pdf [07/08/2021]. evident overload in the symbology which, as mentioned before, is one of the main causes of maps' misinterpretation. Since "hazard maps only serve their purpose if they are properly interpreted" (Kunz, Hurni, 2008, p. 133), different solutions could be adopted to remedy this problem. Firstly, as proposed by Staněk et al. (2010), a possible way could be - when applicable - to combine "various graphical variables in relationship to the feature they are representing" (p. 326). Secondly, the strategy adopted by the Institut Geològic de Catalunya (Martí et al., 2009) for the avalanche bulletin of the Catalan Pyrenees, may constitute a valid alternative. There, the corresponding danger level of each region is indicated through the use of different colour shades; further information can be assumed by selecting each region on the map. Likewise, improvements in the Swiss avalanche bulletin confirmed that the use of dynamic maps could help facilitate their readings (Kunz, Hurni, 2008), and allow users to visualize the different danger areas and get the contents needed by interactively selecting them (Ruesch et al., 2013), which prevent readers to be overwhelmed by information.

Furthermore, the possibility of individually selecting what to read would allow to enrich maps with further contents, without however overloading them. In this regard, and with reference to the strategy adopted by the National Avalanche Warning Service for Norway, such interactive maps would increase awareness and trigger interest to learn more about avalanche dangers and, in so doing, they would hopefully be more effective in preventing deaths and losses of value (Engeset, 2013, p. 302).

\section{Conclusions}

Cartography has proved to be a valid communication and risk prevention tool. Given the possibilities offered by new cartographic digital systems endowed with remarkably user-friendly interfaces, such as many GIS, the contribution that maps can provide for preventive purposes is even greater, and applicable also in the medium-long term (Barbolini et al., 2011; Delparte et al., 2011). Moreover, it cannot be underestimated that, as visual and symbolic supports, maps are also a versatile communication tool suitable for different targets (Staněk et al., 2010).

The paper has pointed out the potential of cartography for the purpose of communicating the avalanche risk, taking as an example the avalanche bulletins of the Meteomont Service of the Alpine Troops Command of Bolzano. The hazard maps included in the bulletin have also provided the opportunity to discuss about the possible limits of this type of communication, thus proving that efficient cartography should be more directed towards interactivity and virtual realities (Kriz, 2001). In fact, as emerged from both previous studies (Kriz, 2001, Staněk et al., 2010) and improvements already applied by various forecasting centres (Kunz, Hurni, 2008; Martí et al., 2009; Engeset, 2013; Ruesch et al., 2013), dynamic and interactive maps allow users to feel involved in the process of creating 
information, as well as to retain these better (Martí et al., 2009); consequently, awareness of forecasted avalanche conditions would increase (Engeset, 2013); at the same time, dynamic and interactive maps make it possible to solve problems from a graphical point of view, such as information and symbolization overload that could hinder the understanding of the information conveyed.

Therefore, far from being exhaustive, this preliminary study aims to provide some informed epistemological insights about effective and efficient cartography, which can also be applied for the purpose of proper avalanche risk communication.

\section{References}

Ancey, C. (2001). Snow avalanches. In Geomorphological fluid mechanics (pp. 319-338). Springer, Berlin, Heidelberg.

Atkins, D. (2000). Human factors in avalanche accidents. In International snow science workshop, Big Sky, MT (pp. 46-51).

Barbolini, M., Pagliardi, M., Ferro, F., \& Corradeghini, P. (2011). Avalanche hazard mapping over large undocumented areas. Natural hazards, 56(2), 451-464.

Bründl, M., Bartelt, P., Schweizer, J., Keiler, M., and Glade, T. (2010). Review and future challenges in snow avalanche risk analysis. In: Geomorphological hazards and disaster prevention. Cambridge University Press, Cambridge, 49-61.

Delparte, D., Jamieson, B., \& Waters, N. (2008). Statistical runout modeling of snow avalanches using GIS in Glacier National Park, Canada. Cold Regions Science and Technology, 54(3), 183-192.

Engeset, R. V. (2013). National avalanche warning service for Norway-established 2013. In Proceedings ISSW (pp. 301-310).

Fredston, J., Fesler, D., \& Tremper, B. (1994, November). The human factor-Lessons for avalanche education. In Proc. 1994 International Snow Science Workshop (pp. 473-487).

Furman, N., Shooter, W., \& Schumann, S. (2010). The roles of heuristics, avalanche forecast, and risk propensity in the decision making of backcountry skiers. Leisure Sciences, 32(5), 453-469.

Gruber, U., \& Margreth, S. (2001). Winter 1999: a valuable test of the avalanche-hazard mapping procedure in Switzerland. Annals of Glaciology, 32, 328-332.

Harley, J. B. (1989). Deconstructing the map. Cartographica: The international journal for geographic information and geovisualization, 26(2), 1-20.

Höppner, C., Bründl, M. and Buchecker, M. (2010). Risk Communication and Natural Hazards. CapHaz-Net WP5 Report, Swiss Federal Research Institute - WSL.

Kriz, K. (2001). Avalanche cartography: visualization of dynamic-temporal phenomena in a mountainous environment. Cartographica: The International Journal for Geographic Information and Geovisualization, 38(12), 77-87.

Kunz, M., \& Hurni, L. (2008). Hazard maps in switzerland. Mountain Mapping and Visualisation, 133.

Martí, G., Pujol, J., Fleta, J., García, C., Oller, P., Costa, O., \& Martínez, P. (2009). A new iconographic avalanche bulletin for the Catalan Pyrenees: a beginning for a future avalanche forecasting database. In Proceedings of the International Snow Science Workshop. Davos, Switzerland (pp. 361-365).

Murphy, A. H. (1993). What is a good forecast? An essay on the nature of goodness in weather forecasting. Weather and forecasting, 8(2), 281-293.

Pravossoudovitch, K., Cury, F., Young, S. G., \& Elliot, A. J. (2014). Is red the colour of danger? Testing an implicit red-danger association. Ergonomics, 57(4), 503-510.

Ruesch, M., Egloff, A., Gerber, M., Weiss, G., \& Winkler, K. (2013). The software behind the interactive display of the Swiss avalanche bulletin. In Proceedings ISSW (pp. 406-412).

Sauermoser, S. (2006). Avalanche hazard mapping-30 years experience in Austria. In Proceedings of the 2006 International Snow Science Workshop in Telluride, Colorado (pp. 1-6).

Scanu G. (2016), Presentazione. In Conoscere per rappresentare. Temi di cartografia e approcci metodologici, Pàtron, Bologna.

Schweizer, J., Bartelt, P., \& van Herwijnen, A. (2021). Snow avalanches. In Snow and ice-related hazards, risks, and disasters (pp. 377-416). Elsevier.

Scott J.C. (2008). Seeing Like a State. How Certain Schemes to Improve the Human Condition Have Failed. In: The Institution for Social and Policy Studies, Yale University Press.

Staněk, K., Friedmannová, L., Kubíček, P., \& Konečný, M. (2010). Selected issues of cartographic communication optimization for emergency centers. International Journal of Digital Earth, 3(4), 316-339.

Steinkogler, W., Sovilla, B., \& Lehning, M. (2014). Influence of snow cover properties on avalanche dynamics. Cold Regions Science and Technology, 97, 121-131.

Takenouchi, K. (2020). Collaborative Community Weather Information. In Disaster Risk Communication (pp. 65-81). Springer, Singapore.

Techel, F., Mitterer, C., Ceaglio, E., Coléou, C., Morin, S., Rastelli, F., \& Purves, R. S. (2018). Spatial consistency and bias in avalanche forecasts-a case study in the European Alps. Natural Hazards and Earth System Sciences, 18(10), 2697-2716.

European Avalanche Service (EAWS): https://www.avalanches.org/.

Meteomont Service

http://www.meteomont.org/. 